\title{
Health Improvements and Health Inequality during the Last 40 Years
}

\author{
Giovanni Andrea Cornia ${ }^{1}$ \\ and Leonardo Menchini ${ }^{2}$
}

February 2006

\begin{abstract}
This paper juxtaposes changes over the last forty years in income growth and distribution with the mortality changes recorded at the aggregate level in about 170 countries and at the individual level in 26 countries with at least two demographic and health surveys covering the last twenty years. Over the 1980s and 1990s, the infant mortality rate, under-5 mortality rate, and life expectancy at birth mostly continued the favourable trends that characterized the 1960s and 1970s. Yet, especially in the 1990s, the pace of health improvement was slower than that recorded during the prior decades. In addition, the distribution between countries of aggregate health improvements became markedly more skewed. These trends are in part explained by the negative changes recorded in sub-Saharan Africa and Eastern Europe, but are robust to the removal of the two regions from the sample. This tendency is observed also at the intraregional level, with the exception of Western Europe. Thirdly, demographic and .../
\end{abstract}

Keywords: health status, health inequality, income inequality, welfare disparities JEL classification: D63, I12, I31, J13, O15

Copyright (c) UNU-WIDER 2006

${ }^{1}$ University of Florence; ${ }^{2}$ UNICEF Innocenti Research Center, and University of Florence

This study is a revised version of the paper presented at the 17-18 June 2005 UNU-WIDER anniversary conference, 'WIDER Thinking Ahead: The Future of Development Economics', directed by George Mavrotas and Anthony Shorrocks.

UNU-WIDER gratefully acknowledges the financial contributions to the research programme by the governments of Denmark (Royal Ministry of Foreign Affairs), Finland (Ministry for Foreign Affairs), Norway (Royal Ministry of Foreign Affairs), Sweden (Swedish International Development Cooperation Agency_Sida) and the United Kingdom (Department for International Development). 
health survey data for 26 developing countries point to a frequent divergence over time in the within-country distribution of gains in the infant mortality and under-5 mortality rates among children living in urban versus rural areas and belonging to families part of different quantiles of the asset distribution. The paper concludes by underscoring the similarities and linkages between changes in income inequality and health inequality and suggests some tentative explanations of these trends without, however, formally testing them.

\section{Acknowledgements}

Work on this paper by Giovanni Andrea Cornia was carried out in the context and with the financial support of the project 'Health and Social Upheaval' sponsored by the MacArthur Foundation.

The preparation of this paper also benefited from earlier research conducted by the authors at the UNICEF Innocenti Research Center for the project 'Harnessing Globalization for Children'. The views expressed herein are those of the authors, and not their respective affiliations. The authors would like to thank Stefano Morandini for his excellent research assistance and participants to the UNU-WIDER Jubilee Conference, held in Helsinki on 17-18 June 2005, for useful comments on a prior version of this paper.

The World Institute for Development Economics Research (WIDER) was established by the United Nations University (UNU) as its first research and training centre and started work in Helsinki, Finland in 1985. The Institute undertakes applied research and policy analysis on structural changes affecting the developing and transitional economies, provides a forum for the advocacy of policies leading to robust, equitable and environmentally sustainable growth, and promotes capacity strengthening and training in the field of economic and social policy making. Work is carried out by staff researchers and visiting scholars in Helsinki and through networks of collaborating scholars and institutions around the world. www.wider.unu.edu publications@wider.unu.edu

UNU World Institute for Development Economics Research (UNU-WIDER)

Katajanokanlaituri 6 B, 00160 Helsinki, Finland

Camera-ready typescript prepared by Lorraine Telfer-Taivainen at UNU-WIDER

The views expressed in this publication are those of the author(s). Publication does not imply endorsement by the Institute or the United Nations University, nor by the programme/project sponsors, of any of the views expressed. 


\section{Introduction}

The debate on the pace of improvement and convergence in levels of wellbeing between and within countries has acquired a particular relevance during the recent decades of economic liberalization and globalization. Though trends in wellbeing can be-and indeed are-affected by non-economic and non-policy factors, sustained improvements and convergence over time in wellbeing indicators across and within countries could be interpreted as an indication of the success of the liberal approach to policy making (Dollar 2001). In turn, slow progress and growing divergence might reinforce the claims of the critics who argue that globalization is inefficient and that-both globally and within each nation - it mainly benefits the upper income groups. The attention received by this debate in policy circles has substantially soared with the adoption of the Millennium Development Goals (MDGs) that have set clear targets for many indicators of wellbeing, including health wellbeing indicators such as infant mortality rate (IMR) and under-five mortality rate (U5MR). The explicit inclusion of health indicators among the MDGs is essential for various reasons. Health is a fundamental dimension of human wellbeing, good health is instrumental for improving other dimensions of wellbeing, and intertemporal and inter-country comparisons based on health wellbeing indicators are less fraught with statistical problems than comparisons effected, for instance, in the monetary space. For all these reasons, this paper focuses on changes in the level and distribution of health wellbeing.

An analysis of changes in health wellbeing can also help shedding light on trends in income wellbeing. In this regard, while the pace of improvement of income per capita over the 1980s and 1990s shows a marked deceleration and an increase in regional variation in relation to the two preceding decades, 1 and while the distribution of withincountry income per capita worsened in most countries, 2 the trend in between-country inequality are unclear, as results of alternative analyses differ considerably depending on the type of statistical assumptions on which these rest. 3 In contrast, analyses of

1 The global growth rate of GDP per capita slowed from 2.6 per cent per annum over the 1960s and 1970s (the second Golden Age of Capitalism) to 1.3 per cent over the 1980s and 1990s (the second Era of Liberalization and Globalization). Growth was particularly weak in the 1990s owing to stagnation in Europe and Japan, the collapse of the European economies in transition, the persistent difficulties faced by Latin America and sub-Saharan Africa, slow growth in MENA and, to a lesser extent, the Asian financial crises. In contrast, China and India recorded rapid growth following the adoption of gradual, pragmatic and selective economic reforms.

2 Cornia (2004) suggests that income inequality rose-though by different extents and with different effects on wellbeing - in 53 of the 73 countries analysed, including China, India, Indonesia, the USA, Japan and Russia. Only in nine small and medium-sized countries inequality appears to have fallen, and only in 16 it remained constant. These country-based results are confirmed by aggregate studies (Bourguignon and Morrisson 2002).

3 Results depend crucially on the inequality index chosen, the period of analysis considered, the 'correct measurement' of the Chinese rate of growth, the weighing of results by population size, whether the comparison is carried out on the basis of GDP per capita (derived from the national accounts) or disposable income per capita (derived from household surveys), and whether the conversion of national GDP values into dollars is done by means of the market or PPP exchange rate. Results depend also on whether the country distributions of income are computed by assigning the same income per capita to all 
health wellbeing are less susceptible of identification, methodological and measurement biases. While problems persist also in this approach, results of analyses of convergence in health wellbeing are less controversial than those based on income wellbeing and could therefore help to investigate on overall trends in wellbeing and the distributive effects of the present development pattern.

\section{Valuing changes in wellbeing}

Traditionally, economists measure wellbeing in the monetary space. In this type of analysis, gains (losses) of wellbeing are associated with a rise (decline) in average incomes or consumption per capita, or with increases in the number of people emerging from (falling into) poverty.

While widely applied, this approach suffers from considerable theoretical and information problems and can, particularly during periods of structural transformation, lead to erroneous conclusions. To start with, unlike in the case of health indicators, which are a direct measure of wellbeing, incomes and wealth are just an input to human wellbeing. However, there are several other factors that influence health wellbeing or education wellbeing, including household assets, human capital, time use, structure and stability of the family, health practices, income inequality and instability, relative prices of essential goods, and public health expenditure. A large number of studies find a positive correlation between income level and health status, but this relation is not linear and unstable and shows a large unexplained variance around the mean. Also, changes in household income normally trigger a series of household and collective responses which can cushion it from the negative health effects of income falls. Indeed, it is not uncommon to observe improvements in health indicators concomitantly with declines in household incomes or, symmetrically, a decline in average health wellbeing and growing health inequality during periods of income growth. Finally, contrary to the common perception, income is not easily definable or measurable, especially in economies with a large subsistence or informal sector and during periods of high inflation, radical fluctuations in relative prices and rapid structural change.

Measurement of average wellbeing and of its distribution among the population, as well as cross-country comparisons, faces fewer methodological problems and does not require the adoption of arbitrary hypotheses and statistical conventions. In addition, the definition and meaning of the variables used-infant mortality rate and life expectancy at birth-is less ambiguous than that of monetary aggregates. Nevertheless, also in this case, national estimates and international comparisons can be complicated by methodological and data availability problems that are briefly reviewed hereafter. The major problem is limited data availability and quality. Vital registration coverage is

citizens, relying on a synthetic statistic such as the Gini coefficient, or building the distribution of income on the basis of micro-data. Finally, results depend on the treatment of large dualistic countries such as China and India, and the inclusion of the 'special case' of China in the calculation of between-country inequality. In contrast, results point to a clear North-South polarization when between-country inequality is assessed not as a ratio of the countries' respective GDPs per capita but as their absolute difference. This aspect of income polarization has, however, been neglected by most of the literature. 
complete or almost complete only in high-and middle-income countries, and only one third of all adult deaths are actually registered.4 In most low-income countries, registration of vital statistics is incomplete, often massively so, and mortality data are estimated by means of life survival tables or by extrapolating past trends. Infant and child mortality are also estimated indirectly from censuses or demographic surveys by means of retrospective techniques. 5 The stability and reliability of these estimates can however be affected by large sampling error, limited sample size and, in low mortality countries, low frequency of infant and child deaths. As a result, it is not uncommon to observe large discrepancies between mortality estimates originating from surveys and register data.

The use of life expectancy at birth (LEB) as an indicator of health wellbeing poses additional problems of interpretation. Such an indicator is in fact computed on the basis of the age specific mortality rates observed for different cohorts at a moment in time. However, as noted in Pradhan et al. (2001), such rates do not reflect the real life chances of a person born in the reference year, as computation of such index would require to know her future risks of death at different ages. As a consequence, LEB does not refer to any individual birth cohort but rather to a hypothetical cohort facing the age specific death rates observed at the present time.

The paper does not concentrate only on average aggregate changes in indicators of health wellbeing but examines, within the limitations imposed by data availability, also the changes intervened in their distribution between and within countries. Steep health differentials have been observed for long in many countries. In the United Kingdom, for instance, the famous Black Report 6 focussed on the marked health gradient observed among different groups of civil servants. Concern for reducing inequality in health was evident also in the WHO 'Health for All' strategy and the related target setting exercises that in 1984 posited that '.. by the year 2000, the actual differences in health status between countries and between groups within countries, should be reduced by at least 25\%' (Whitehead 1990, cited in Gwatkin 2000). Meanwhile, concern for the health impact of economic policies intensified with the introduction of structural adjustment programmes that may have shifted the policy focus away from the search of 'health for all' and the achievement of the MDGs.

Finally, an emphasis on health differentials is justified by several arguments. First, according to most theories of justice, an average improvement in IMR or LEB characterized by high variation around the mean receives a lower social valuation than an equal average improvement characterized by a more egalitarian distribution. Second, targeting health intervention on the deprived groups generally permits achieving faster average gains than if it were targeted at the general population. For instance, high rates of child and adult mortality in poor rural areas can be reduced by low-cost public health

\footnotetext{
4 WHO (2005).

5 UN (2004).

6 Black et al. (1980).
} 
interventions, while the further reduction of already low mortality rates in urban areas is costly and difficult to achieve. Greater equity in health can thus be a source of greater aggregate efficiency. Third, large health differentials, or their increase over time, may exacerbate the perception of unfairness of social relations and raise political instability. Finally, a rise in health differentials, or their persistence at high levels, collides with the emphasis placed by the Human Rights Convention (HRC) on the wellbeing of every individual. Rapid improvements limited only to a few groups and to the average do not satisfy the prescriptions of the HRC and MDGs.

\section{Literature on changes in health wellbeing and its distribution}

\subsection{Pace of improvement in health wellbeing}

Most of the literature in this area examines the pace of changes over the last two decades without comparing it to that realized over prior decades. In reviewing changes in IMR, LEB and life expectancy at age 1, for instance, Fox (1998) emphasizes that progress continued uninterrupted for all these indicators for both developing and developed countries, but does not assess whether these gains took place at a similar, faster or slower pace than in the past. Likewise, in analyzing changes in LEB over 1980-2000, Goesling and Firebaugh (2004) note that the increase in LEB in the 1990s in rich countries was smaller than that recorded in the developing countries but do not compare it with that recorded over the prior two decades. In contrast, Wagstaff and Cleason (2004) note that, in the 1990s, progress in U5MR reduction was slower than in the 1980s, while Deaton (2004) points to a worldwide reduction in the rate of decline of child mortality and to slower gains in child mortality in many countries. In turn, Deaton and Drèze (2002) underscored that in India IMR declined in the 1990s by only 12.5 per cent as against 30 per cent in the 1980s. Also the World Development Report 20067 points to a slowdown in the rate of increase in LEB during the 1990s.

\subsection{Between-country convergence in health wellbeing}

Over the past three decades, most demographers predicted growing convergence in health wellbeing between developing and developed countries. Wilson (2001), for instance, found that LEB had steadily converged across countries starting from 1950. Meyer (2001), in turn, focused on club convergence, by emphasizing that the (unweighed) distribution of LEB across countries remained twin-peaked over 1960-97 despite the 'migration' of several countries from the left to the right peak and the increase in the mode of the two components of this bi-modal distribution. Thus, convergence towards a life expectancy of 45-50 years was evident within the low-LEB club of poor countries and 75-80 years within the high-LEB club of rich ones.

In turn, Micklewright and Stewart (1999) found that the standard deviation of the distribution of U5MR of the 15 members of the European Union declined over 1970-95

\footnotetext{
7 World Bank (2005).
} 
by 90 per cent as death rates in the countries of southern Europe moved closer to those of northern Europe. Convergence was also found, if less markedly, for the mortality rate of children of 5-14 years of age. This convergence was to a considerable extent policydriven. Indeed, the EU Cohesion Fund has provided structural and regional funds equivalent to 3-4 per cent of the GDP of the recipient countries to help them catch up with the EU average. Participation in the EU favoured the convergence in health wellbeing also through the compulsory adoption of advanced standards-the so-called acquis communautaires - in the field of health services.

In contrast, the most recent analyses point to growing between-country health inequality owing to the dramatic rise in mortality rates recorded in sub-Saharan Africa (SSA)and Eastern Europe, the slow gains recorded in China despite a quadrupling of GDP/c over 1980-2000, and poor health performance of other countries. In this regard, Goesling and Firebaugh (2004) analyze the distribution of LEB of 169 countries for the period 19802000. They note that while increasing during the 1980s in all regions, LEB declined over 1990-2000 in SSA and the transition economies. These divergent paths have led to a polarization of the country distribution of LEB, as confirmed by the upward trend recorded since 1992 in four synthetic indexes of the distribution of life expectancy. According to the authors, LEB inequality declined until 1992 to increase significantly between 1992-2000. A decomposition of this inequality rise into changes in population shares and life expectancy ratios led them to conclude that-although only one-tenth of the world's population lives in SSA - the HIV/AIDS impact on LEB (-3.5 years on average, as opposed to a worldwide increase of 1.2 years) was the main factor in LEB divergence. When SSA was removed from the sample, the divergence in national LEB disappeared as the fall in life expectancy in the transition economies was compensated by the rapid rise recorded in populous India.

Also McMichael et al. (2004) also find evidence that contradicts the finding about LEB convergence. They identify in fact three sets of countries, the first (composed mainly of advanced nations) with a plateauing LEB trend, a second group of middle-income countries converging rapidly towards the LEB of the advanced nations, and a third group comprising at least 42 countries (mostly from SSA and the economies in transition, but including also the Bahamas, the Dominican Republic, Fiji, Haiti, Honduras, Iraq, and North Korea) that exhibited in 2001 a lower life expectancy than in 1960, 1980 or 1990 . In their view, the usual explanation of health convergence-i.e., the rapid fall in deaths due to infectious diseases in poorer countries and the slower decline in mortality due to chronic diseases-has to be broadened so as to take into account new life-threatening challenges faced in the economic, social and environmental areas.

\subsection{Within-country convergence in health indicators and mortality differentials}

Health differentials are observed in practically all countries, including the most advanced ones. One of the most important IMR differentials is that by level of education of the mother (Caldwell 1979). Greater education among mothers is also 
found to reduce the IMR gender differential. 8 Mortality rates also correlate strongly with the region and, in particular, the type (rural or urban) of residence, that proxy different access to sanitation, housing, health and educational services. 9 Health differentials by income level are equally marked. 10

Another point, central to the analysis of this paper, is that in more egalitarian countries, mortality differentials are not as glaring as in unequal societies. Hardly ever a class-, gender- and region-neutral development policy is able to reduce mortality differentials, even in the presence of sizeable average improvements. For instance, an analysis of survey data on inequalities in U5MR by consumption quintiles found statistically significant inequalities in most of the nine countries analyzed.11 Such differentials were particularly pronounced in highly unequal Brazil where an IMR concentration index of -0.322 was found. In contrast, the index was -0.016 in Vietnam and -0.028 in Ghana, i.e. countries where consumption inequality was less pronounced. In turn, Wilkinson (1996) compared IMR by social class in England and Wales versus Sweden, and discovered a marked social gradient in the first countries but not in Sweden, a country strongly committed to reducing health inequality.

Growing U5MR differentials by income level are reported by Minujin and Delamonica (2003) on demographic and health survey (DHS) data for the 1980s and 1990s for 24 developing countries. In the 1980s the ratio of the U5MR of children of families belonging to the bottom 20 per cent of the household 'asset' 12 distribution to that children of households belonging to the top 20 per cent ranged between 1.3 to 4.7, with an average of 2.2. However, over the next ten years the ratio worsened in 11 of the 24 countries studied, remained constant in 10 and improved in three. Such trend was observed not only in countries where the average U5MR worsened or stagnated, but also in half of those where it fell. In these countries, the average U5MR reduction was mostly driven by a decline in child mortality among middle- and high-income groups. Meanwhile, the reduction among the poor was lower or statistically not different from zero.

A recent analysis of IMR differentials in China making use of census and survey data by Zhang and Kanbur (2003) found that, while the nationwide IMR declined sharply from the 1960s to the 1980s, it then levelled off or was reversed in recent times due to the surge in rural IMR from 37 to 44.8 per thousand between 1981 and 1995 . As a result, the ratio of rural to urban IMR rose from 1.5 to 2.1, the female to male IMR ratio

\footnotetext{
8 Murthi et al. (1995).

9 Sastry (1996); Jhamba (1999).

10 Rutstein (2000).

11 Wagstaff (2000).
}

12 The 'asset index' is used to proxy household wealth and income and is used to stratify households into quintiles. It is constructed following the procedure described in Filmer and Pritchett (1998) that weights the possession of certain household durables (such as radios and bicycles), the quality of dwellings (as revealed by the type of roof and floor) and access to different kinds of water and sanitation facilities. 
rose from 0.9 to 1.3, and the Gini index of the regional distribution of IMR worsened. The authors explain these trends to the fiscal decentralization of 1978, the dismantling of commune-based health services, the introduction of private care in 1984 and the freedom granted to urban-based state-owned enterprises (SOEs) to lay off workers and cut health subsidies. The authors conclude by noting that, given the weakness of safety nets and social insurance arrangements and limited fiscal power of villages, it was to be expected that increases in income inequality would translate into increasing health inequality.

\section{Trends in the pace of improvement in health wellbeing}

Conscious of the methodological and data problems encountered in measuring health wellbeing, the values for the IMR, U5MR and 100-LEB (see later) were compiled for the years 1960, 1970, 1980, 1990, and 2000 for 168 countries on the basis of the World Development Indicators of the World Bank (2004). Missing data for several former communist countries of Europe were filled in on the basis of the data included in the UN Population Prospects 2002 revision.13 Average, population weighted, compounded rates of change over the 1960s, 1970s, 1980s and 1990s were then computed for all main regions and country groupings, and for China and India separately. Analysis of these data points to the following results:

\subsection{A widespread decline over the 1990s in the pace of improvement in 100-LEB}

An analysis of changes over time in LEB risks leading to a biased conclusion as the variable LEB is upper bounded at, say, 100 years of age14_a fact that automatically forces smaller absolute and relative gains in countries with an already high life expectancy. Thus, barring cases of extreme deteriorations, this method of calculation is unable to provide a balanced picture of the real progress realized in overall survival. To avoid this problem, typically met in measuring progress in upper bounded variables, it was necessary to calculate the average annual compounded rate of change of the difference between 100 (the arbitrarily assumed upper bound of LEB) and its observed values. The variable 100-LEB measures the 'life years lost in relation to the maximum attainable LEB' and has the advantage of being scale invariant, which means that rates of improvement are independent from the base value of the variable. For instance, in this framework, a two-year rise in LEB in a country with a LEB of 80 years generates a 10 per cent improvement, that is identical to that generated by a rise of 6 years in a country with a LEB of 40.

\footnotetext{
13 See UNPD (2002).

14 Such upper bound is arbitrary, as the maximum attainable life duration varies over time and across countries with the development of medical technologies and other factors. Over the medium term, however, it is undeniable that we face some kind of immutable genetic maximum that cannot be changed by an increase in resources or medical services. While the choice of 100 is arbitrary, the results of the analysis would not change much if instead an upper bound of, say, 90 or 110 years had been chosen (see later).
} 
Table 1: Levels and annual population-weighed percentage average rates of change in (100-LEB) by main regions and key countries, 1960-2000

\begin{tabular}{|c|c|c|c|c|c|c|c|c|c|}
\hline & \multicolumn{5}{|c|}{ Levels } & \multicolumn{4}{|c|}{ Average annual rate of change } \\
\hline & 1960 & 1970 & 1980 & 1990 & 2000 & $60-70$ & $70-80$ & $80-90$ & $90-100$ \\
\hline High-income countries & 31 & 29 & 26 & 24 & 22 & -0.64 & -1.04 & -0.86 & -0.84 \\
\hline Low- and middle-income countries: & 56 & 45 & 40 & 37 & 36 & -2.14 & -1.12 & -0.80 & -0.35 \\
\hline Low- and middle-income excl. China, India & 51 & 46 & 41 & 38 & 38 & -1.03 & -1.08 & -0.79 & -0.14 \\
\hline \multicolumn{10}{|l|}{ Macro regions* } \\
\hline East Asia and Pacific* & $61^{\star *}$ & 41 & 36 & 33 & 31 & $-3.94^{* *}$ & -1.37 & -0.83 & -0.56 \\
\hline China & $64^{\star *}$ & 38 & 33 & 31 & 30 & $-4.97^{* *}$ & -1.42 & -0.63 & -0.45 \\
\hline East Asia and Pacific excl. China & 54 & 48 & 42 & 37 & 34 & -1.14 & -1.35 & -1.30 & -0.85 \\
\hline Eastern Europe and Central Asia & 35 & 32 & 32 & 31 & 32 & -0.73 & 0.06 & -0.52 & 0.28 \\
\hline Latin America and Caribbean & 44 & 40 & 35 & 32 & 30 & -0.99 & -1.10 & -0.98 & -0.78 \\
\hline Middle East and North Africa & 53 & 48 & 42 & 36 & 32 & -1.06 & -1.29 & -1.58 & -1.05 \\
\hline South Asia & 56 & 51 & 46 & 42 & 38 & -0.92 & -0.97 & -1.11 & -0.99 \\
\hline India & 56 & 51 & 46 & 41 & 37 & -0.94 & -0.99 & -1.14 & -0.97 \\
\hline South Asia excl. India & 58 & 53 & 48 & 44 & 39 & -0.86 & -0.91 & -1.03 & -1.08 \\
\hline SSA & 60 & 56 & 52 & 50 & 53 & -0.68 & -0.63 & -0.45 & 0.66 \\
\hline World & $50^{*}$ & 41 & 37 & 35 & 34 & $-1.83^{\star}$ & -1.00 & -0.74 & -0.36 \\
\hline World excl. SSA & $48^{*}$ & 40 & 36 & 33 & 31 & $-1.91^{*}$ & -0.92 & -0.86 & -0.62 \\
\hline World excl. SSA and EECA & $50^{*}$ & 41 & 37 & 33 & 31 & $-2.04 *$ & -1.06 & -0.88 & -0.71 \\
\hline
\end{tabular}

Source: Authors’ calculations based on World Bank (2004), integrated with data from UNPD (2002). Notes: *High income countries are not included in the macro regions, e.g. East Asia does not include Japan; **these values are influenced by the famine that hit China during the 1958-62 'Great Leap Forward'.

Table 1 presents trends in 100-LEB and its annual compounded percentage rate of change. 15 It documents the rapid gains recorded over the 1960s and 1970s thanks to the development of national health systems and the adoption of modern health technologies in newly independent states. In the socialist countries of Europe such gains were less pronounced and indeed they stagnated in 1970s due to 'chronic stress' 16 while in the 1990s 100-LEB rose markedly because of a sharp rise in cardiovascular and violent deaths caused by 'acute stress' induced by a difficult transition to the market economy. 17 As a result, in 2000 100-LEB in this region was the same as in 1970. The table documents also the massive loss of life expectancy caused in SSA by HIV/AIDS and, to a lesser degree, by economic stagnation, eroding health services, rising inequality and local conflicts. The table also show that the rate of decline in (100-LEB)

15 The regional averages and the measures of dispersion presented in the paper are always weighted by the appropriate populations (live births for IMR, the whole population for 100-LEB, etc.). Trends in the unweighted averages and inequality measures are mostly omitted for reasons of space. As expected, they show a greater variability than the weighted ones, though they broadly confirm the trends identified above.

16 Bobak and Marmot (1996).

17 Cornia and Paniccià (2001). 
varies considerably across regions, and that the best results were achieved in the 1960s in Africa and Eastern Europe, the 1970s in East Asia, Latin America and the highincome group, the 1980s in MENA and India and the 1990s in the South Asian countries other than India (thanks to the rapid mortality decline recorded in Bangladesh).

The main message of Table 1 concerns, however, the steady and generalized decline in the rate of progress in 100- LEB, a decline that is robust to the removal of SSA and Eastern Europe from the sample and to the change of the upper bound of LEB from 100 to 90.18 Besides the cases of Eastern Europe and SSA, a marked slowdown in relation to the prior decade is evident also in China and the East Asian economies, and a less pronounced one in Latin America, MENA and India. In contrast, the slowdown recorded in high-income countries is modest, suggesting the possibility of continued gains even at low levels of 100-LEB. The second main message is that such slowdown was most pronounced in the 1990s, possibly suggesting, with the exception of South Asia, the impact of systemic development problems or the impact of covariant random shocks.

\subsection{A fairly widespread decline over the $1990 \mathrm{~s}$ in the rate of improvement in IMR}

Table 2 presents the rates of change of IMR over the period 1960-2000. In many developing countries, infant deaths represent a large share of total deaths, and IMR is considered a key indicator of overall health. U5MR is an even more accurate predictor of overall health, but information on such variable is available for only 156 countries. For this reason, as well as for reasons of space, the paper presents only the results of the analysis of IMR trends. 19

As noted in Fox (1998), the last two decades witnessed a continuation of the improvements in child health indicators recorded over 1960-80. In fact, the 1980s recorded the fastest decadal rate of decline in IMR in Latin America, MENA and India, while acceptable rates of IMR decline were sustained in East Asia, Eastern Europe and the high-income countries. The fast IMR decline in Latin America and MENA during the 1980s is both remarkable and puzzling, in view of the recession experienced by both regions and of the debt, budgetary and inequality crises suffered by Latin America.20 Continued progress was likely due to a rise in parental literacy and female education. An even greater role was played by the spread of low-cost health technologies and community-based approaches to health, among which immunization and oral rehydration played an important part. As shown in Figure 1, the coverage of DPT3

\footnotetext{
18 The rates of improvement are sensitive to the choice of the upper bound. Yet, the conclusions do not change significantly in case the arbitrary upper bound chosen is 90 , so as to generate the variable 90-LEB, that is 'the life years lost in relation to the maximum attainable LEB of 90'.

19 The U5MR analysis is available from the authors. Its results support the conclusions of the IMR analysis.

20 In contrast, in MENA the public health expenditure/GDP ratio remained at a high 4-5 per cent of GDP during the entire decade. In addition, the region recorded a massive rise in female education made possible by generous allocations of public funds to education staring from the 1970s.
} 
immunization rose in Latin America from below 40 per cent in 1980 to 75 per cent in 1990. In MENA, the expansion was even more rapid. In India, progress in immunization in the 1980s was accompanied by a widespread and fairly egalitarian growth. Table 2, however, also shows that the rate of IMR reduction fell in the 1990s in all but two regions. In China, India, MENA and Eastern Europe the fall was sizeable. The decline is evident also at the global level, and is robust to the elimination of SSA and Eastern Europe from the sample.

Table 2: Levels and annual average population-weighed average percentage rates of change in IMR by main regions and key countries, 1960-2000

\begin{tabular}{|c|c|c|c|c|c|c|c|c|c|}
\hline & \multicolumn{5}{|c|}{ Levels } & \multicolumn{4}{|c|}{$\begin{array}{c}\text { Average annual rate of } \\
\text { change }\end{array}$} \\
\hline & 1960 & 1970 & 1980 & 1990 & 2000 & $60-70$ & $70-80$ & $80-90$ & $90-00$ \\
\hline High-income countries & 36 & 22 & 12 & 8 & 6 & -4.8 & -5.9 & -4.0 & -2.8 \\
\hline Low- and middle-income countries: & 138 & 107 & 86 & 69 & 62 & -2.5 & -2.2 & -2.2 & -1.1 \\
\hline Low- and middle-income excl. China and India & 129 & 111 & 94 & 75 & 70 & -1.4 & -1.7 & -2.2 & -0.7 \\
\hline \multicolumn{10}{|l|}{ Macro regions* } \\
\hline East Asia and Pacific* & $134^{\star \star}$ & 85 & 56 & 43 & 34 & $-4.4^{\star *}$ & -4.1 & -2.6 & -2.3 \\
\hline China & $150^{*}$ & 85 & 49 & 38 & 32 & $-5.5^{\star}$ & -5.4 & -2.5 & -1.7 \\
\hline East Asia and Pacific excl. China & 91 & 85 & 72 & 52 & 38 & -0.7 & -1.7 & -3.1 & -3.2 \\
\hline Eastern Europe and Central Asia & 68 & 53 & 45 & 37 & 32 & -2.5 & -1.6 & -1.9 & -1.4 \\
\hline Latin America and Caribbean & 102 & 86 & 61 & 43 & 31 & -1.7 & -3.4 & -3.4 & -3.2 \\
\hline Middle East and North Africa & 163 & 131 & 94 & 57 & 46 & -2.2 & -3.3 & -4.9 & -2.1 \\
\hline South Asia & 147 & 129 & 115 & 88 & 71 & -1.3 & -1.1 & -2.6 & -2.1 \\
\hline India & 146 & 127 & 113 & 84 & 68 & -1.4 & -1.2 & -2.9 & -2.1 \\
\hline South Asia excl. India & 150 & 135 & 121 & 99 & 79 & -1.0 & -1.1 & -2.0 & -2.3 \\
\hline SSA & 164 & 141 & 116 & $110^{* \star *}$ & $104^{\star \star \star}$ & -1.5 & -1.9 & $-0.5^{\star \star \star}$ & $-0.6^{\star * *}$ \\
\hline World & 122 & 97 & 79 & 64 & 57 & -2.3 & -2.0 & -2.1 & -1.2 \\
\hline World excl. SSA & 115 & 91 & 72 & 54 & 45 & -2.3 & -2.2 & -2.8 & -1.9 \\
\hline World excl. SSA and EECA & 119 & 93 & 75 & 56 & 45 & -2.4 & -2.2 & -2.9 & -2.0 \\
\hline
\end{tabular}

Notes: income countries are not included in the macro regions, e.g. East Asia does not include Japan ** these values are influenced by the famine that hit China during the 1959-61 'Great Leap Forward'. *** The WDI IMR data for SSA for the 1980s and 1990s have been recently revised and describe a less dramatic trend in the 1990s. Such revision is however puzzling as a main factor in infant mortality has been the rise in HIV adult prevalence rate in the 1990s.

Source: Authors' calculations on World Bank (2004) and UNPD (2002).

It has been argued that such a widespread deceleration was due to three factors. First, the levelling of vaccination coverage at rates that do not guarantee 'herd immunity'. Second, in regions with IMR below 30-40 per thousand, the slowdown might be due to the elimination of all 'easy-to-remove' causes of infant death and to the difficulties faced in dealing with complex and costly peri-natal problems. Third, the quasistagnation (or, according to other data, the rise) of IMR in SSA was also explained by the surge in AIDS deaths among infants. Regression analysis by Cornia and Zagonari (2002), for instance, shows that a one percentage rise in HIV adult prevalence rate 
raised IMR by 0.88 points. This means that in countries with high HIV prevalence (say, 20 per cent) IMR rose, ceteris paribus, by 17 points per thousand. While pertinent, these explanations do not tell the whole story and can hardly explain the slowdown in IMR in MENA, the transition economies, China and the high-income countries. A broader set of factors is, therefore, likely to have been at play.

Figure 1: Global and regional trends in DPT3 coverage, 1980-2003

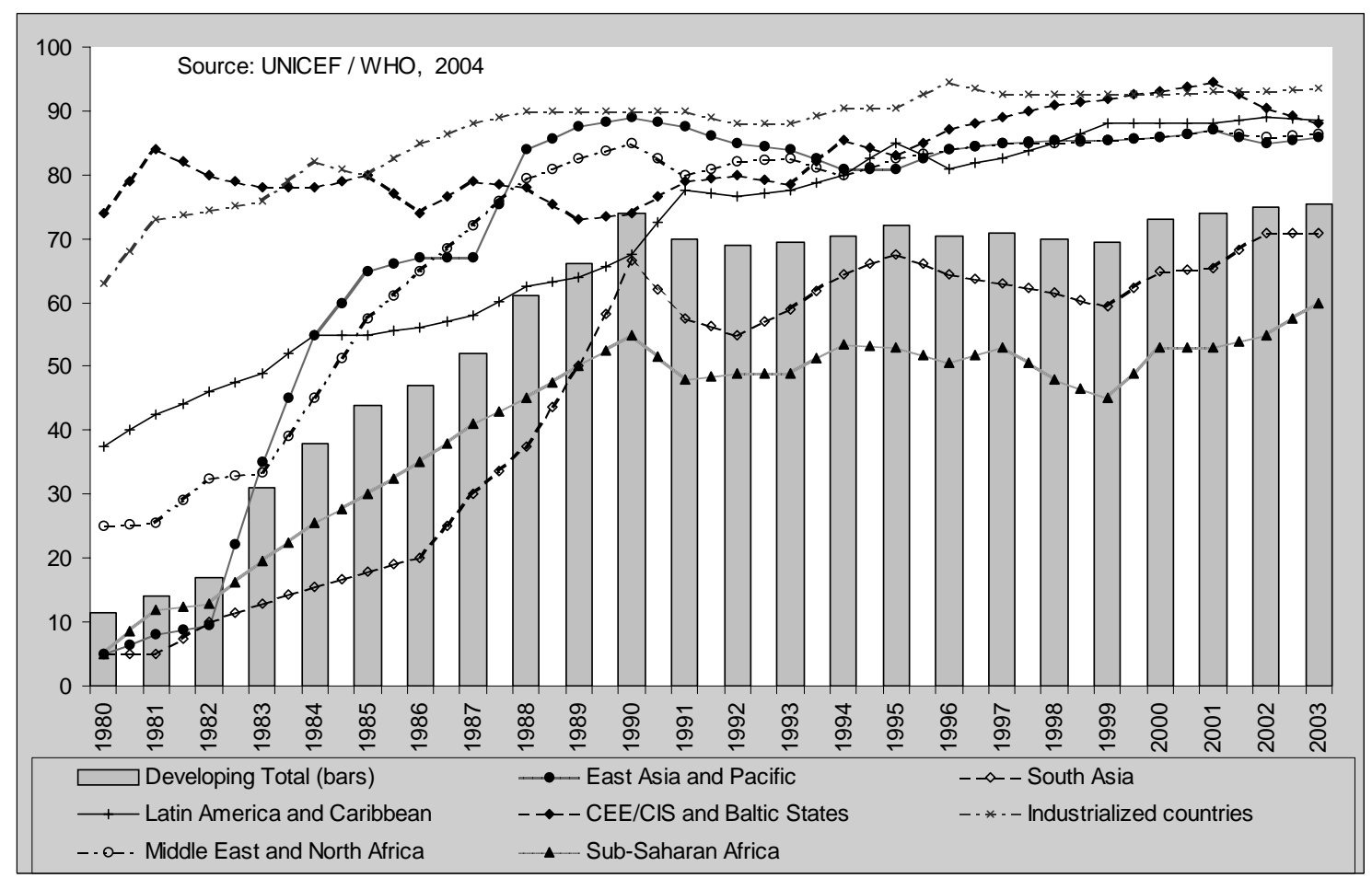

\section{Trends in between-countries distribution of health wellbeing}

The last decade has also witnessed a perceptible increase in between-country health inequality, as mortality declined at different rates in different nations. Growing health inequality is observed also within most regions, suggesting that the pace of progress differed also within groups of countries characterized by similar socioeconomic conditions. If continued, this polarization in health wellbeing may lead to rising spillovers of 'international public bads' (disease, refugees, drugs and illegal migration).

\subsection{Rising global and regional inequality in the distribution of (100-LEB)}

Table 3 presents the weighted and unweighted coefficient of variation and Gini coefficient 21 of the global and regional distributions of 100-LEB for the years 1960,

21 The coefficient of variation (CV) is the ratio of standard deviation to average ${ }_{C V}=\frac{\sqrt{\sum_{i}\left(y_{i}-\bar{y}\right)^{2} n_{i}}}{\sum_{i} y_{i} n_{i}}$ 
1970, 1980, 1990 and 2000. At the world level, both the coefficient of variation and the Gini index follow a U-shaped pattern, with the distribution of 100-LEB converging until 1990 and then diverging. However, as also suggested by Goesling and Firebaugh (2004), such divergence disappears if SSA is removed from the sample, as the fairly rapid convergence recorded in South Asia (India and Bangladesh in particular) and Central Europe (the Czech Republic and Poland) compensated the divergence registered in countries of the former Soviet Union and in nations such as Iraq, North Korea, and Haiti.

Table 3: Trend in the coefficient of variation and Gini coefficient of the intraregional and global distribution of 100-LEB, 1960-2000

\begin{tabular}{|c|c|c|c|c|c|c|c|c|c|c|}
\hline & \multicolumn{5}{|c|}{$\begin{array}{l}\text { Coefficient of variation } \\
\text { (pop. weighted values) }\end{array}$} & \multicolumn{5}{|c|}{ Gini coefficient (pop. weighted values) } \\
\hline & 1960 & 1970 & 1980 & 1990 & 2000 & 1960 & 1970 & 1980 & 1990 & 2000 \\
\hline East Asia and Pacific (22) & 0.18 & 0.16 & 0.16 & 0.15 & 0.15 & 7.98 & 7.23 & 7.48 & 6.51 & 6.17 \\
\hline L. America and Caribbean (32) & 0.12 & 0.12 & 0.12 & 0.12 & 0.13 & 6.54 & 6.17 & 6.40 & 6.20 & 6.49 \\
\hline Middle East and N. Africa (20) & 0.10 & 0.10 & 0.10 & 0.12 & 0.14 & 3.61 & 4.06 & 4.99 & 6.06 & 6.78 \\
\hline SSA (45) & 0.07 & 0.08 & 0.09 & 0.11 & 0.09 & 3.70 & 4.33 & 5.10 & 5.90 & 4.59 \\
\hline South Asia (7) & 0.05 & 0.06 & 0.07 & 0.07 & 0.08 & 1.61 & 1.89 & 2.11 & 2.12 & 1.94 \\
\hline E. Europe and C. Asia (29) & 0.15 & 0.13 & 0.08 & 0.05 & 0.10 & 6.81 & 5.55 & 4.18 & 2.88 & 5.44 \\
\hline W. Europe (18) & 0.05 & 0.04 & 0.04 & 0.04 & 0.04 & 2.29 & 2.12 & 2.29 & 2.10 & 1.92 \\
\hline North America (2) & n.a. & n.a. & n.a. & n.a. & n.a. & n.a. & n.a. & n.a. & n.a. & n.a. \\
\hline World (175) & 0.27 & 0.24 & 0.24 & 0.23 & 0.27 & 15.2 & 13.32 & 13.19 & 12.86 & 14.18 \\
\hline World excl. SSA (130) & 0.28 & 0.22 & 0.22 & 0.20 & 0.19 & 15.63 & 12.57 & 11.98 & 10.87 & 10.31 \\
\hline World excl. SSA \& EECA (101) & 0.26 & 0.22 & 0.22 & 0.20 & 0.20 & 14.47 & 12.21 & 12.32 & 11.31 & 10.67 \\
\hline \multicolumn{11}{|l|}{ Memo item: unweighted values } \\
\hline World (175) & 0.27 & 0.27 & 0.28 & 0.30 & 0.35 & 15.4 & 15.6 & 16.0 & 16.8 & 19.4 \\
\hline World excl. SSA (130) & 0.25 & 0.24 & 0.23 & 0.23 & 0.24 & 14.2 & 13.3 & 12.5 & 11.8 & 12.5 \\
\hline
\end{tabular}

Notes: the number of countries in each area is in parenthesis. The population of the countries included in this analysis represents over 99 per cent of the world population.

Source: Authors' calculations on World Bank (2004).

Table 3 shows also that the intraregional dispersion in (100-LEB) followed a U-shaped trend in Eastern Europe but a continuously diverging one in most other regions with the exception of East Asia and Western Europe which registered a clear convergence. Interestingly, in SSA there was a 'downward convergence' in 100-LEB between 1990 and 2000 as the countries that suffered the biggest losses of life expectancy (South

The Gini-type index used for the study of IMR disparity is $\operatorname{GINI} I M R=\left[\sum_{i=0}^{N-1}\left(y_{i+1}+y_{i}\right)\left(x_{i+1}-x_{i}\right)\right]-1$ where the countries (i) are ordered by decreasing IMR level, $y$ is the cumulated proportion of infant deaths, and $x$ is the cumulated proportion of the infant population. These two indicators of dispersion are scale invariant, they are easy to interpreter and are among the most used indicators in the economic literature on disparities. This is an important characteristic in the view of a multidimensional analysis of disparities in wellbeing. Moreover the Gini index is increasingly used in the study of health inequalities and some adaptation to health indicators have been elaborated (e.g. for IMR). 
Africa, Botswana and so on) were those which had the highest LEB in the 1980s. Except for East Asia, that is dominated by China, these trends are more pronounced when the coefficient of variation and the Gini index are computed without weighing the life expectancy data by population size. An analysis of health dispersion trends making use of the variable 90-LEB (instead of 100-LEB) shows that divergence in global health distribution start emerging in the 1980 (rather than in 1990) but confirms the U-shaped pattern of health inequality trends and that the 1990s was the decade with the strongest rise of inter-regional and global health inequality.

It must finally be noted that when the coefficients of dispersion are computed without weighing country data for population size, the global divergence in health inequality persists in the 1990s even after removing SSA from the sample (bottom of Table 3). All this means that, in terms of countries rather than people, the derailment of long-term convergence in life expectancy predicted by Preston (1976) and Wilson (2001) is due to factors other than the spread of HIV/AIDS, stagnation and conflicts in Africa. This is a key point noted in McMichael et al. (2004) that should be brought to the attention of policymakers.

Goesling and Firebaugh (2004) have suggested that rising global inequality in 100-LEB (the 'actual change') may be due more to faster population growth in regions characterized by higher values of 100-LEB (the 'population effect') than to differences in the rate of change in 100-LEB itself (the 'growth effect'). To test this hypothesis, the observed change in the Gini coefficient of the distribution of 100-LEB was decomposed into these components. The results in Table 4 indicate that differences in population growth explain a small part of the global changes both for the world as a whole and for the World excluding SSA. Most of the rise in the Gini coefficient is imputable to the 'growth effect'.

Table 4: Decomposition of yearly changes in Gini of 100-LEB ('actual change') into the 'population effect' and 'growth effect' (\% changes)

\begin{tabular}{llrrr}
\hline & & $1970-80$ & $1980-90$ & $1990-2000$ \\
\hline \multirow{3}{*}{ World } & actual change & -0.10 & -0.25 & 0.98 \\
& growth effect & -0.01 & -0.22 & 0.83 \\
& Population effect & -0.19 & -0.09 & 0.07 \\
& & & & \\
\multirow{2}{*}{ World excluding SSA } & actual change & -0.48 & -0.97 & -0.53 \\
& growth effect & -0.37 & -0.84 & -0.51 \\
& Population effect & -0.18 & -0.11 & 0.02 \\
\hline
\end{tabular}

Note: The 'growth effect' is the average yearly change in the Gini coefficient of the global distribution of 100-LEB using the countries' population weights of 1970. The 'population effect' is the average yearly change in the Gini coefficient of the global distribution of 100-LEB keeping the level of the countries' 100LEB at its 1970 value.

Source: Authors' calculation based on World Bank (2004). 


\subsection{Increasing global and intraregional dispersion in the distribution of IMR}

Table 5 presents the trend of the coefficient of variation and of the Gini coefficient of the population-weighed regional and global IMR distributions for the years 1960, 1970, 1980, 1990 and 2000. The table confirms that, because of country differences in rates of IMR reduction (Table 2), the coefficient of variation and Gini index of the global distribution of IMR have shown a clear upward trend from 1980 onward, while during the prior two decades there was only a modest increase. This trend is robust, if in a slightly attenuated way, to the removal of SSA and Eastern Europe from the sample. This means that the gains in IMR recorded during the last two decades have been distributed in an increasingly unequal way across countries and that several of them have been left behind.

Divergence in the global distribution of IMR is found also when the analysis is conducted on unweighted data. Removing SSA from the sample does not alter visibly this result (bottom of Table 5). Thus, also in this case, SSA accounts for part of the rise in IMR divergence but not for its entirety. Other forces are hampering the decline of IMR in several regions.

Table 5: Coefficient of variation and Gini coefficient of the intraregional and global distribution of IMR

\begin{tabular}{|c|c|c|c|c|c|c|c|c|c|c|}
\hline & \multicolumn{5}{|c|}{$\begin{array}{l}\text { Coefficient of variation } \\
\text { (pop._weighted values) }\end{array}$} & \multicolumn{5}{|c|}{$\begin{array}{c}\text { Gini coefficient } \\
\text { (pop. weighted values) }\end{array}$} \\
\hline & 1960 & 1970 & 1980 & 1990 & 2000 & 1960 & 1970 & 1980 & 1990 & 2000 \\
\hline East Asia and Pacific (22) & $0.31^{*}$ & 0.28 & 0.38 & 0.39 & 0.46 & $15.2^{\star}$ & 12.5 & 18.4 & 17.1 & 17.8 \\
\hline L. America and Caribbean (27) & 0.26 & 0.26 & 0.34 & 0.38 & 0.40 & 14.2 & 13.8 & 18.0 & 19.9 & 19.7 \\
\hline Middle East and N. Africa (20) & 0.21 & 0.26 & 0.29 & 0.37 & 0.56 & 10.6 & 13.5 & 15.6 & 20.3 & 28.4 \\
\hline SSA (45) & 0.24 & 0.23 & 0.25 & 0.28 & 0.25 & 12.8 & 13.0 & 13.9 & 15.3 & 13.8 \\
\hline South Asia (8) & 0.09 & 0.11 & 0.13 & 0.17 & 0.27 & 2.50 & 4.0 & 4.4 & 5.3 & 8.8 \\
\hline Eastern Europe and C.Asia (26) & 0.57 & 0.78 & 0.68 & 0.60 & 0.61 & 28.5 & 38.8 & 33.8 & 31.9 & 32.9 \\
\hline Western Europe (18) & 0.37 & 0.35 & 0.26 & 0.14 & 0.18 & 19.0 & 17.5 & 12.6 & 6.5 & 9.4 \\
\hline North America (2) & n.a. & n.a. & n.a. & n.a. & n.a. & n.a. & n.a. & n.a. & n.a. & n.a. \\
\hline World (168) & $0.41^{*}$ & 0.43 & 0.51 & 0.57 & 0.64 & $22.2^{\star}$ & 24.0 & 29.0 & 33.1 & 35.1 \\
\hline World excl. SSA (123) & $0.42^{*}$ & 0.44 & 0.53 & 0.55 & 0.61 & $22.6^{*}$ & 24.3 & 30.1 & 30.5 & 32.6 \\
\hline World excl. SSA\&EECA (97) & $0.39 *$ & 0.41 & 0.51 & 0.54 & 0.60 & $20.4^{\star}$ & 22.4 & 28.8 & 29.7 & 32.1 \\
\hline \multicolumn{11}{|l|}{ Memo item: unweighted values } \\
\hline World (168) & $0.54^{*}$ & 0.61 & 0.71 & 0.82 & 0.90 & $30.2^{\star}$ & 35.1 & 39.9 & 44.8 & 48.8 \\
\hline World excl. SSA (123) & $0.58^{\star}$ & 0.67 & 0.77 & 0.85 & 0.96 & $32.9^{*}$ & 37.3 & 41.5 & 44.5 & 48.3 \\
\hline
\end{tabular}

Notes: * these values are influenced by the famine that hit China during the 1958-61 'Great Leap Forward'. The number of countries in each area is in parenthesis. The population of the countries included in this analysis represents over 99 per cent of the World infants' population.

Source: authors' calculations on World Bank (2004). 
Rising inequality in the distribution of IMR since 1980 is evident also in MENA, South Asia, East Asia and Latin America. In the first three of these regions, the fastest increase in intraregional divergence in IMR took place over 1990-2000, a period characterized by slow and volatile growth, mounting income inequality and stagnant or declining coverage of key public health programmes in favour of children. The exception to this rule are the two 'crisis regions' of Eastern Europe and SSA both of which show fluctuating trends characterized by a 'downward convergence' in IMR in the 1980s and 1990s, as in both regions the worst performance was recorded in countries with already fairly low IMR levels. In contrast, the distribution of national IMRs improved steadily in Western Europe (save for a blip over 1990-2000 that disappears when using unweighted data) confirming the findings about the policy-driven equalization of health wellbeing in the region. 22

To conclude, the analysis of IMR convergence confirms-more markedly than in the case of 100-LEB - that the recent global and intraregional health gains were distributed in an increasingly less egalitarian way, particularly over the 1990s. This conclusion is robust to the choice of different inequality and health indicators, and to the weighting of national indicators by means of appropriate populations.

\section{Trends in the within-country distribution of health wellbeing}

This kind of analysis is made possible by the increase in the number of countries 23 with at least two demographic and health surveys 24 over the last twenty years. These surveys permit, in principle to carry out assessments of changes in health differentials on the basis of several indicators. Information gaps, however, limit such choice and, for this reason, the analysis will focus exclusively on IMR 25 differentials for children belonging to different quintiles of the income distribution or residing in urban versus rural areas. Analysis of changes in IMR differentials by level of education of the mother is possible in principle but is biased by the under-sampling of highly educated mothers, and is thus omitted from the analysis.

\footnotetext{
22 Micklewright and Stewart (1999).

23 The countries with at least two DHS surveys are, at this date, about 40 . The 26 countries included in this analysis are Benin, Burkina Faso, Cameroon, Cote d’Ivoire, Ghana, Kenya, Madagascar, Malawi, Mali, Niger, Nigeria, Rwanda, Senegal, Tanzania, Togo, Uganda, Zambia, Zimbabwe, Brazil, Colombia, Dominican Republic, Egypt, India, Bangladesh, The Philippines and Indonesia. The size of the DHS samples vary considerably not only between countries (ranging from 92,486 households coverage by the 1998/99 DHS for India to 1,381 households of the 1999 DHS in the Dominican Republic) but also between different rounds of DHS in the same country (for example in Malawi the households covered by the survey were 2,798 in 1996 and 14,213 in 2000).
}

24 DHS are large-scale nationally representative household surveys of varying sample size. This analysis used data on children based on interview of women aged 15-49 or 15-44 containing information about births and surviving children of 60 (or 36) months of age at the time of the survey.

25 The IMRs used in the analysis of differentials by rural-urban are calculated dividing the number of infant deaths under one year of age by the number of births in the five complete years preceding the survey, considering also half of the deaths occurred at age 12 months, which strictly speaking is included in the second year of life, but which probably occurred in the first year. In contrast, the mortality differentials by the asset index are computed on the ten years preceding the survey. 


\subsection{Trends in IMR differentials by income level}

As shown in the literature (see section 3), DHS now permit to estimate the mortality risk of infants ranked by an 'asset index' that proxies household income. In this regard, Table 6 presents the values of IMR at two different points in time for 16 developing countries, both for the sample's average and for the bottom and top quintile of the household asset distribution. The table provides also two measures of dispersion, i.e. the interquitile ratio (IQR), the ratio of the IMR of children belonging to the bottom and top quintiles of the asset distribution, and the concentration coefficient (CC) of the same distribution. While the former index captures changes in the tails of the IMR distribution, the latter is more sensitive to changes affecting the three central quintiles.

Table 6: Trends in IMR and IMR differentials for 16 developing countries, 1990s and early 2000 s

\begin{tabular}{|c|c|c|c|c|c|c|c|c|c|c|}
\hline \multirow{2}{*}{ Country (and survey years) } & First & riod (ea & ly 1990 & & \multicolumn{4}{|c|}{ Second period } & \multirow[t]{2}{*}{$\begin{array}{l}\text { Change in } \\
\text { inter- } \\
\text { quintile } \\
\text { ratio }\end{array}$} & \multirow[t]{2}{*}{$\begin{array}{c}\text { Change in } \\
\text { concen- } \\
\text { tration } \\
\text { coeff. }\end{array}$} \\
\hline & Total & $1^{\text {st }} \mathrm{Q}$ & $5^{\text {th }} \mathrm{Q}$ & $1^{\text {st }} / 5^{\text {th }}$ & Total & $1^{\text {st }} \mathrm{Q}$ & $5^{\text {th }} \mathrm{Q}$ & $1^{\text {st }} / 5^{\text {th }}$ & & \\
\hline & IMR & IMR & IMR & Ratio & IMR & IMR & IMR & Ratio & & \\
\hline Turkey $(1993,1998)$ & 68.3 & 99.9 & 25.4 & 3.9 & 48.4 & 68.3 & 29.8 & 2.3 & decline & decline \\
\hline Kazakhstan $(1995,1999)$ & 40.7 & 39.2 & 35.1 & 1.1 & 54.9 & 67.6 & 42.3 & 1.6 & rise & rise \\
\hline Colombia $(1995,2000)$ & 30.8 & 40.8 & 16.2 & 2.5 & 24.4 & 32.0 & 17.6 & 1.8 & decline & rise \\
\hline Guatemala $(1995,1998)$ & 57.2 & 56.9 & 35.0 & 1.6 & 49.1 & 58.0 & 39.2 & 1.5 & decline & constant \\
\hline Haiti $(1994-95,2000)$ & 87.1 & 97.3 & 74.3 & 1.3 & 89.4 & 99.5 & 97.2 & 1.0 & decline & decline \\
\hline Nicaragua $(1997-98,2001)$ & 45.2 & 50.7 & 25.8 & 1.9 & 35.3 & 49.6 & 16.3 & 3.0 & rise & rise \\
\hline Peru (1996, 2000) & 49.9 & 78.3 & 19.5 & 4.0 & 43.2 & 63.5 & 13.9 & 4.6 & rise & - \\
\hline Egypt $(1995,2000)$ & 72.9 & 109.7 & 31.8 & 3.4 & 54.7 & 75.6 & 29.6 & 2.6 & decline & decline \\
\hline Bangladesh (1996-97, 1999-2000) & 89.6 & 96.5 & 56.6 & 1.7 & 79.7 & 92.9 & 57.9 & 1.6 & decline & rise \\
\hline India (1992-93, 1999) & 86.3 & 109.2 & 44.0 & 2.5 & 73.0 & 96.5 & 38.1 & 2.5 & constant & - \\
\hline Nepal $(1996,2001)$ & 93.0 & 96.3 & 63.9 & 1.5 & 77.2 & 85.5 & 53.2 & 1.6 & rise & rise \\
\hline Cameroon $(1991,1998)$ & 80.3 & 103.9 & 51.2 & 2.0 & 79.8 & 108.4 & 55.8 & 1.9 & decline & - \\
\hline Ghana $(1993,1998)$ & 74.7 & 77.5 & 45.8 & 1.7 & 61.2 & 72.7 & 26.0 & 2.8 & rise & rise \\
\hline Malawi $(1992,2000)$ & 136.1 & 141.2 & 106.1 & 1.3 & 112.5 & 131.5 & 86.4 & 1.5 & rise & rise \\
\hline Mali $(1995,2001)$ & 133.5 & 151.4 & 93.2 & 1.6 & 126.2 & 137.2 & 89.9 & 1.5 & decline & rise \\
\hline Uganda $(1995,2000-01)$ & 86.1 & 109.0 & 63.2 & 1.7 & 89.4 & 105.7 & 60.2 & 1.8 & rise & - \\
\hline
\end{tabular}

Note: the IMRs are calculated over the 10 years preceding the survey.

Source: authors' elaboration on data provided by the World Bank, Health, Nutrition, Population and Poverty Division (www.worldbank.org/hnp).

The evidence presented in Table 6 shows that average IMR fell over time in 12 of the 16 countries analyzed, stagnated in 1 and worsened in 3. Progress in average IMR, however, was accompanied in 60 per cent of the cases by a rise in IMR inequality 
indexes that are used here jointly as they provide different information about health inequality. 26

A cross-tabulation of changes in average IMR and IMR inequality (Table 7) further shows that in many instances an average IMR improvement was accompanied by growing or unchanged IMR inequality. The upper right box of Table 7 shows, for instance, that in 12 cases concerning eight countries most of the IMR decline benefited children from higher quintiles. In three cases concerning two countries IMR inequality worsened, as expected, in parallel with a rise in average IMR while in another three IMR inequality fell despite a rise in IMR. These results confirm the findings of Minujin and Delamonica (2003) for the mid 1980s and mid 1990s about a widespread rise in U5MR inequality despite a fall in the mean.

Table 7: Cross tabulation of changes in average IMR versus the interquartile ratio (IQR) and concentration coefficient (CC) for 26 inequality changes concerning 16 countries

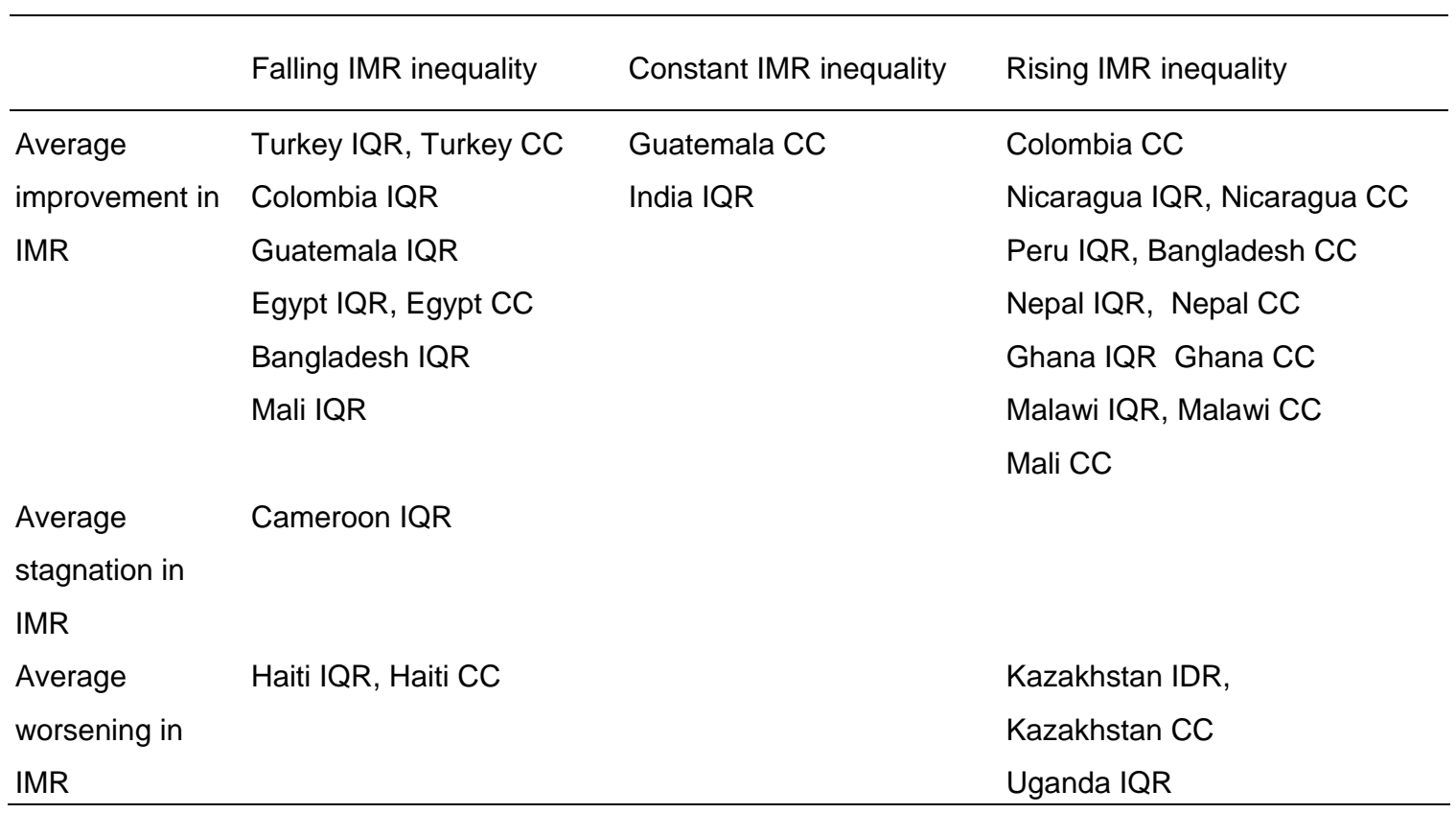

Note: changes of less than 4 per cent are assumed to indicate that the variable remained constant.

Source: Authors' compilation on the basis of the data report in Table 6.

\subsection{Trends in IMR differentials by rural vs. urban residence}

In this case the rural-urban IMR differentials were calculated on DHS surveys spanning the period 1985-99. DHS analysts normally compute IMR differentials over a 10-year period so as to enlarge the sample and reduce the estimation error. This procedure has the disadvantage, however, to preclude practically all analyses of changes in IMR levels and differentials for an entire decade. For this reason, the IMR differentials were computed for 5-year periods so as to be able to capture the changes in IMR over the

26 The worsening of IMR differentials was more frequent in the case of the concentration coefficient. 
1990s, and because when a longer period is chosen there is a higher risks that the mothers included in the sample are age selected and that recall errors will be larger. The decision to compute IMR differentials for 5-year periods, however, reduces the sample size and may affect the stability of IMR estimates. As in other cases, the data may also be affected by errors common in this kind of survey, such as omission of registrations, misreporting of age, recall error, and so on. Be as it may, the analysis was conducted assigning each survey to four sub-periods 1985-90, 1991-95, 1996-2000 and 2001-03 (Table 8).

Table 8: IMR national level and rural-urban IMR ratio in selected countries

\begin{tabular}{|c|c|c|c|c|c|c|c|c|}
\hline & \multicolumn{2}{|c|}{$1985-90$} & \multicolumn{2}{|c|}{ 1991-95 } & \multicolumn{2}{|c|}{$1996-2000$} & \multicolumn{2}{|c|}{ 2001-03 } \\
\hline & IMR & $\mathrm{R} / \mathrm{U}$ & IMR & $\mathrm{R} / \mathrm{U}$ & IMR & $\mathrm{R} / \mathrm{U}$ & IMR & $\mathrm{R} / \mathrm{U}$ \\
\hline Benin & & & & & 98 & 1.19 & 94 & 1.55 \\
\hline Burkina Faso & & & 103 & 1.56 & 114 & 1.79 & & \\
\hline Cameroon & & & 67 & 1.10 & 83 & 1.39 & & \\
\hline Cote d'Ivoire & & & 91 & 1.21 & 117 & 1.42 & & \\
\hline Ghana & 89 & 1.33 & 71 & 1.31 & 60 & 1.61 & 68 & 1.31 \\
\hline Kenya & & & 65 & 1.22 & 68 & 1.38 & 80 & 1.31 \\
\hline Madagascar & & & 98 & 1.47 & 100 & 1.19 & & \\
\hline Malawi & & & 143 & 1.11 & 110 & 1.62 & & \\
\hline Mali & 123 & 1.54 & & & 130 & 1.49 & 128 & 1.25 \\
\hline Niger & & & 136 & 1.67 & 130 & 1.77 & & \\
\hline Nigeria & 96 & 1.25 & & & 83 & 1.26 & & \\
\hline Rwanda & & & 88 & 0.97 & 114 & 1.51 & & \\
\hline Senegal & & & 71 & 1.68 & 74 & 1.54 & & \\
\hline Tanzania & & & 95 & 0.76 & 93 & 1.29 & 103 & 1.05 \\
\hline Togo & 87 & 1.08 & & & 84 & 1.32 & & \\
\hline Uganda & 108 & 1.03 & 86 & 1.15 & & & 92 & 1.78 \\
\hline Zambia & & & 111 & 1.32 & 116 & 1.09 & 100 & 1.21 \\
\hline Zimbabwe & 52 & 1.51 & 55 & 1.3 & 70 & 1.15 & & \\
\hline Brazil & 75 & 1.82 & & & 40 & 1.86 & & \\
\hline Colombia & 35 & 1.02 & 29 & 1.22 & 22 & 1.12 & & \\
\hline Dominican Rep. & 70 & 1.03 & 44 & 1.46 & 47 & 1.28 & 32 & 1.15 \\
\hline Egypt & & & 64 & 1.73 & 45 & 1.34 & 39 & 1.41 \\
\hline India & & & 81 & 1.52 & 78 & 1.57 & & \\
\hline Bangladesh & & & 91 & 1.52 & 84 & 1.11 & 68 & 1.07 \\
\hline The Philippines & & & 36 & 1.46 & 37 & 1.27 & & \\
\hline Indonesia & & & 71 & 1.47 & 47 & 1.52 & 35 & 1.63 \\
\hline
\end{tabular}

Source: Authors' calculations on selected DHS. 
Table 8 shows that in the mid-to-late 1980s, the majority of the SSA countries had fairly high average IMR but moderate rural-urban gap, ranging between 1.03 and 1.5. Differentials were somewhat more pronounced in Brazil where the rural-urban IMR ratio exceeded 1.8. In many cases, the changes observed between the 1980s and 1990s point to an exacerbation of such differentials though in some cases the gap narrowed. Altogether, in thirteen cases out of the 26 sample countries the rural-urban IMR ratio worsened between the first and last survey, in four it remained broadly unchanged and in nine it narrowed. In Indonesia the rural-urban gap worsened despite a decline in the nationwide IMR, while the opposite was true in Bangladesh and the Philippines. The three Latin American countries in the sample show moderate deterioration or stagnation between the initial and final year. As a whole, the trends observed in SSA do not permit to identify a clear relation between IMR reduction and rural-urban IMR convergence. Generally speaking, rural areas continue to be disadvantaged with respect to infant health. In all cases, a greater focus on rural areas would have allowed to achieve a faster overall decline in IMR — and a more balanced distribution of health wellbeing.

Table 9: Cross tabulation of IMR changes in relation to changes in the rural-urban $(\mathrm{r} / \mathrm{u})$ IMR ratio in selected developing countries, mid-late 1980 s to early 2000 s

\begin{tabular}{llll}
\hline & Falling r/u IMR ratio & Constant r/u IMR ratio & Increasing r/u IMR ratio \\
\hline $\begin{array}{l}\text { Average improvement } \\
\text { in IMR }\end{array}$ & $\begin{array}{l}\text { Zambia, Egypt, } \\
\text { Bangladesh }\end{array}$ & $\begin{array}{l}\text { Ghana, Nigeria, } \\
\text { Brazil }\end{array}$ & $\begin{array}{l}\text { Indonesia, Malawi, } \\
\text { Uganda, Colombia, }\end{array}$ \\
Average stagnation & Madagascar, Mali, The India & Dominican Rep. \\
in IMR & $\begin{array}{l}\text { Philippines, Senegal, } \\
\text { Tanzania }\end{array}$ & Benin, Togo, Niger & 9 \\
Average worsening & Zimbabwe & & \\
& & & Burkina Faso, \\
& & Cameroon, Kenya, \\
& & Cote d'Ivoire, \\
\end{tabular}

Note: Changes of less than 4 per cent are taken to indicate that the variable has remained constant.

Source: Author's elaboration on selected DHS.

Also in this case, a cross-tabulation of changes in average IMR versus the rural-urban IMR differentials in Table 9 shows there are many off-diagonal observations. In fact, eleven countries located above the main diagonal recorded worse-than-expected changes in IMR differentials, i.e. stable or rising IMR differential on occasion of average improvements, or a worsening of this ratio on occasion of a stagnation of average IMR. In contrast, there were only six countries below the main diagonal showing better-than-expected results. All this points to a comparatively high frequency of deteriorations in the urban-rural IMR ratio explained by the faster progress realized in urban areas and revealing the limits of location-neutral policies. 


\section{Conclusions and indications for further research}

The data problems mentioned throughout this paper suggest caution in interpreting the above results. Yet, the above discussion points to a few important conclusions, some fairly robust, some still tentative. To start with, over the last twenty years the rate of improvement in health wellbeing slowed down in relation to that recorded in the 1960s and 1970s. In developing and transitional countries, the slowdown was most pronounced in the 1990s. However, there are important exceptions to this rule (such as MENA and Latin America in the 1980s) that need to be investigated in greater detail to identify the factors that permitted continuing progress in health wellbeing in spite of flat or negative growth and, in the case of Latin America, rising inequality. Yet, the slowdown in rates of progress was sufficiently general to suggest the effect of some systemic factors. Indeed, the slowdown is robust to the removal of SSA and Eastern Europe from the sample, thus invalidating the viewpoint that attributes the current slowdown to the difficulties of the transition in Eastern Europe and the spread of AIDS, civil conflicts and economic stagnation in SSA. Thus, though with some exceptions and differences in time profiles, the slowdown in aggregate rates of improvement in health wellbeing in the 1908s and 1990s seems to be fairly general.

Second, there is clear evidence that the between-country distribution of health wellbeing has become more skewed. This conclusion holds also after removing SSA and Eastern Europe from the sample. In addition, with the exception of Western Europe and East Asia (in the case of 100-LEB) and of Western Europe and Eastern Europe (in the case of IMR), the intraregional distribution of health gains has become increasingly less egalitarian. These are important conclusions as, so far, there is little agreement in the literature on the wellbeing convergence over the last two decades. The paper also suggests that where public policy actively aimed at reducing wellbeing differentials, as in the EU, health wellbeing converged steadily.

Finally, the within-country distribution of health wellbeing by an asset index and ruralurban location appears to have worsened in about 50-60 per cent of the cases analyzed. Such trends need however to be confirmed on a longer time period and bigger samples but seem to corroborate the results mentioned at the beginning about the worsening of the income distribution.

What are the factors behind these changes in health wellbeing? In view of data problems and the level of aggregation of the analysis, the points made below are at times speculative and must be taken as hypotheses to be tested by detailed analyses rather than firm conclusions on causality. To start with, there is no doubt that the spread of HIV/AIDS affected in a major way trends in IMR and 100-LEB in SSA and a few Caribbean countries and that - barring new breakthroughs in medical research and drugs availability-HIV/AIDS will continue to affect negatively health wellbeing trends in these countries in the years ahead. It is important to note in this regard that, as in the 1990s, future AIDS-related mortality will be influenced by the way globalization (and in particular the TRIPS agreement) will affect the cost and transfer of health technology (anti-retrovirals in particular) in the areas affected by the pandemic. As noted by Deaton 
(2004), if this transfer is delayed or is too costly, mortality differentials across regions will continue to diverge because of these policies.

Yet, it is not possible to place all the blame for the unsatisfactory health performance of the last decade on HIV/AIDS, especially in countries with low HIV prevalence but a record of slow health improvements and growing health inequality. In this regard, a second possible cause of the slow health improvement and growing divergence in health wellbeing are changes in health spending and key health programmes. The debate about globalization has often highlighted the risk posed to revenue collection by liberal tax reforms, tax competition among developing countries and the globalization-driven outsourcing and informalization of the economy. Yet, the evidence on revenue collection and public expenditure is mixed. While there are examples of countries (such as China and the economies in transition) that restricted public health expenditure and access to health services, in others (from MENA and Latin America) public health expenditure increased or remained constant at relatively high levels. However, public health expenditure may be too noisy a variable to affect mortality rates. In contrast, an expansion of key public health programmes such as child immunization, oral rehydration, provision of antibiotics, and pregnancy control, can deliver important health gains even during periods of stagnant health expenditure. Symmetrically, a stagnation or decline in the coverage of such programmes (as often observed in the 1990s for immunization) may have affected adversely IMR and LEB even in the presence of an expanding health budget.

Third, mortality has also been affected by a rising wave of local conflicts and natural disasters. Those of Afghanistan, Angola, Bosnia, Burundi, Cambodia, Ethiopia, Guatemala, Iraq, North Korea, Rwanda, Somalia, Sri Lanka and Sudan are just a few of the 50 or so humanitarian crises in which death rates soared markedly. Yet, only crude estimates of the health impact of such crises are available and only in few cases is it possible to fully capture the impact of these tragic events on mortality trends, as existing databases generally underreport their impact.

Fourth, changes in the structure and stability of households-and in social cohesion more generally - may have also affected, if more subtly, current health trends. The traditional family has in fact been eroded in many places thus exposing its members to greater health risks, as suggested by micro studies that identify a greater death risk of children, elderly and adults living in incomplete families. In this regard, the last twenty years have seen a rise in the number of people living in incomplete households because of divorce, separation, lone parenthood, singlehood, migration and premature death of the parents or of a spouse. Single-parent families represent 10-15 per cent of all OECD families with dependent children and a higher percentage in Latin America, the Caribbean and parts of South East Asia. Such trend has surfaced even in China where traditional values usually left no space for such types of family arrangement. In turn, in the HIVaffected countries the number of orphans exposed to risk of non-AIDS-related mortality has risen well above the level that can be handled through extended family arrangements. In other countries, such as Bosnia and Ethiopia, war and ethnic conflicts have caused a sharp increase in the number of incomplete families. Meanwhile in Russia, Moldova and 
other economies in transition, the number of biological or social orphans has risen rapidly because of soaring parental mortality, migration and child abandonment.

Last but not least, a host of empirical data and theoretical arguments suggest that health trends have been affected by the slow or negative growth and soaring income inequality observed over the last twenty years in many developing and transition countries that adopted botched liberalization and globalization policies such as loose bank deregulation, premature external liberalization and regressive tax reforms. Indeed, both theory and empirical evidence show that slower growth, greater income inequality and rising volatility affect health and health inequality. 27 The precise extent and mechanisms of such impact remain however undocumented in most cases. This is a priority area for research in which existing theories linking growth and income inequality to health and health inequality have to be tested on enlarged datasets and time periods. Perhaps, this new research will help bringing about a more humane globalization promoting faster health progress and health convergence over the next decades.

\section{References}

Black, D., J. Morris, C. Smith, and P. Townsend (1980). Inequality in Health: Report of a Research Working Group (The Black Report), Department of Health and Social Security: London.

Bobak, M., and M. Marmot (1996). 'East-West Mortality Divide and its Potential Explanations: Proposed Research Agenda’, British Medical Journal 312: 421-3.

Bourguignon, F., and C. Morrisson (2002). 'Inequality among World Citizens: 18201992', The American Economic Review 92(4): 727-44.

Caldwell, J.C. (1979). 'Education as a Factor in Mortality Decline: an Examination of Nigerian Data’, Population Studies 33(3): 395-413.

Cornia, G.A. (2004) 'Inequality, Growth and Poverty in an Era of Liberalization and Globalization’, Oxford University Press for UNU-WIDER: Oxford.

\footnotetext{
27 Much is known about the relation between income inequality and health inequality. To start with, it is generally accepted that, as the relation between income per capita and life expectancy is concave, an increase in income inequality will—ceteris paribus — cause a fall in life expectancy among the poor and middle class bigger than the gain in life expectancy among the rich. Second, high inequality reduces access to health care by the poor both because these have a lower income to buy it in the market and as high inequality reduces the state capacity to tax the elites and so provide subsidized health services. Third, there evidence that high inequality raises the crime rate and the number of violent deaths. Fourth, there is initial evidence that, at least in advanced countries and transitional economies, high inequality leads to loss in social cohesion that affect the ability of communities to undertake collective action, to a hierarchal organization of work causing loss of control and worse health outcomes, and to rising psychosocial stress. Finally, there is considerable, though not universally accepted, evidence that high-income inequality affects health status via a decline in GDP growth. Indeed, most theories and empirical analyses suggest that lower growth GDP would result because of low investment in human capital, increased macroeconomic disequilibria and balance of payment instability, decreasing returns to capital, rising social instability, declining work incentives, and growing policy distortions and government failures.
} 
Cornia, G.A., and R. Paniccià (2000). 'The Mortality Crisis of Transitional Economies', Oxford University Press for UNU-WIDER: Oxford.

Cornia, G.A., and F. Zagonari (2002). 'An Econometric Investigation of Changes in IMR and U5MR in AIDS Affected Countries During the Last Twenty Years', mimeo, UNICEF-IRC: Florence.

Deaton, A. (2004). 'Health in an Age of Globalization', NBER Working Papers 10669, National Bureau of Economic Research: Cambridge MA.

Deaton, A., and J. Drèze (2002). 'Poverty and Inequality in India: A Re-Examination', Centre for Development Economics Working Papers 107, Delhi School of Economics: Delhi.

Dollar, D. (2001). 'Is Globalization Good for Your Health?', Bulletin of the World Health Organization 79(9): 827-33.

Filmer, D., E.M. King, and L. Pritchett (1998). 'Gender Disparity in South Asia: Comparison between and within Countries', Policy Research Group Working Papers 1867, World Bank: Washington DC.

Fox, J.W. (1998). 'Gaining Ground. World Wellbeing 1950-95', USAID Evaluation Special Study Report 79, USAID: Washington DC.

Goesling, B., and G. Firebaugh (2004). 'The Trend in International Health Inequality', Population and Development Review 30(1): 131-46.

Gwatkin, D.R. (2000). 'Health Inequalities and the Health of the Poor: What Do We Know? What Can We Do?', Bulletin of the World Health Organization 78(10): 318.

Jhamba, T. (1999). 'Regional Variation in Childhood Mortality in Zimbabwe', Geography 84(4): 319-30.

McMichael, A, M. McKee, V. Skolnikov, and T. Valkonen (2004). 'Mortality Trends and Setbacks: Global Convergence or Divergence?’, The Lancet 363(9415): 1155-9.

Meyer, D. (2001). 'Convergence Clubs in Cross-Country Life Expectancy Dynamics', WIDER Discussion Papers 2001/134, UNU-WIDER: Helsinki.

Micklewright, J., and K. Stewart (1999). 'Is the Wellbeing of Children Converging in the European Union?’, The Economic Journal 109(459): F692-714

Minujin, A., and E. Delamonica (2003). 'Mind the Gap! Widening Child Mortality Disparities', Journal of Human Development 4(3): 397-418.

Murthi, M., A.-C. Guio, J. Drèze (1995). 'Mortality, Fertility and Gender Bias in India: A District-Level Analysis’, Population and Development Review 21(4): 745-82. 
Pradhan, M., D.E. Sahn, and S.D. Younger (2001). 'Decomposing World Health Inequality’, Tinbergen Institute Discussion Papers 01-091/2, Tinbergen Institute: Amsterdam.

Preston, S.H. (1976). Mortality Patterns in National Populations, Academic Press: New York.

Rutstein, S.O. (2000). 'Factors Associated with Trends in Infant and Child Mortality in Developing Countries During the 1990s', Bulletin of the World Health Organization 78(10): 1256-70.

Sastry, N. (1996). 'Community Characteristics, Individual and Household Attributes, and Child Survival in Brazil’, Demography 33(2): 211-29.

UN (2004). Handbook on the Collection of Fertility and Mortality Data, United Nations Department of Economic and Social Affairs: New York

UNPD (United Nations Population Division) (2002). World Population Prospects: the 2000 Revision, United Nations: New York

Wagstaff, A. (2000). 'Socioeconomic Inequalities in Child Mortality: Comparison across Nine Developing Countries', Bulletin of the World Health Organization 78(1):19-29.

Wagstaff, A., and M. Cleason (2004). 'Raising to the Challenge', World Bank: Washington DC.

Wilkinson, R.G. (1996). Unhealthy Societies: The Afflictions of Inequality, Routledge: London and New York.

Wilson, C. (2001). 'On the Scale of Global Demographic Convergence', Population and Development Review 27(1): 155-71.

World Bank (2004). World Development Indicators 2004 CD-Rom, World Bank: Washington DC.

World Bank (2005). World Development Report 2006: Equity and Development, World Bank: Washington DC.

WHO (2005). World Health Report 2005: Make Every Mother and Child Count, World Health Organization: Geneva.

Zhang, X. and R. Kanbur (2003). 'Spatial Inequality in Education and Health in China', mimeo, International Food Policy Research Institute: Washington DC. 